\title{
Two-year Death Transition of Activities of Daily Living among Non-institutionalized Elderly in the US
}

J. Phys. Ther. Sci.

12: $1-5,2000$

\author{
Hiroshi UedA ${ }^{1)}$, Tomoaki Shimada ${ }^{2)}$ \\ ${ }^{1)}$ Leonard Davis School of Gerontology, University of Southern California, University Park, \\ MC-0191, Los Angeles, CA 90089-0191, USA. TEL +1 213-740-0656 \\ ${ }^{2}$ Faculty of Health Sciences, Kobe University School of Medicine
}

\begin{abstract}
This study examined the two-year death transition of the different status of activities of daily living (ADLs) among the elderly who were aged 70 and over. The study used the data from the Assets and Health Dynamics of the Oldest Old (AHEAD) data set, which contains a nationally representative sample within subgroups of the non-institutionalized population of the United States. Multiple logistic regression analyses were applied for each sex while socio-demographic factors were controlled. We found that both men and women with a higher number of ADL limitations indicated higher odds for death within two years compared with people without ADL limitations at the baseline interview $(p<0.01)$. A significant higher odds ratio was also indicated for the death of people who had ADL limitations compared with the people without any ADL limitations in some ADL categories. There were somewhat different results between men and women. Different functional status for men and women at the baseline might result in the different death outcomes.
\end{abstract}

Key words: Elderly, Activities of daily living (ADLs), Mortality.

(This article was submitted Sep. 2, 1999, and was accepted Nov. 5, 1999)

\section{INTRODUCTION}

Activities of daily living (ADLs) are designed to assess the functions of the chronically ill and aged populations ${ }^{1)}$. The assessment of ADLs is frequently used to test the physical function among the elderly. It provides information for health providers and researchers about the self-care ability of an individual. In general, people with less ability to perform ADL activities are more likely to use services than people with greater abilities ${ }^{2)}$.

Knowing the dynamics of health transitions through physical limitations is critically important to understand and explain the common change in functional status among the elderly. Physical function may improve, stay the same, or worsen over time from previous studies ${ }^{3-7)}$. The worst outcome from physical limitations is death. However, previous longitudinal studies have not compared people with and without functional problems in terms of the changes of each limitation and numbers of ADL limitations to death by using a representative sample of the whole elderly population of the United States. We examined the relationship between different ADL status and death with a nationally representative sample.

\section{SUBJECTS AND METHODS}

Our study used the data set of the Assets and Health Dynamics of the Oldest Old (AHEAD). The AHEAD Study has a longitudinal design with biennial follow-ups. This study sample basically represents the non-institutionalized elderly who were aged 70 and over and their spouses in the 
United States. In this study, we used data from two waves. The first data collection was conducted from October 1993 through July 1994, and the second collection began November 1995 and was concluded June 1996. The total number of respondents interviewed in wave I was 8,223 . In this study, we used 7,443 individuals who were aged 70 or over at the wave I interview. This group consisted of 2,908 men (39.1\%) and 4,535 women $(60.9 \%)$. The average ages were $77.2 \pm 5.7$ years for men and $77.9 \pm 6.0$ years for women.

With this sample, six categories of self-reported activities of daily living were retrieved from Wave I and II of the AHEAD data set. These are walking, dressing, bathing, eating, getting in/out of bed, and using the toilet. These variables were dichotomized as to whether there was any problem or not.

Multiple logistic regression analyses for each sex were conducted for two multivariate models: the number of ADL limitations and each ADL function. Socio-demographic factors were controlled for both logistic models. Weighting factors based on the 1990 Census were used to adjust for geographic and racial differences in sampling rates. This weight adjustment was already provided in the data set.

\section{RESULTS}

Two-year death rates increased as the number of ADL problems increased, according to the baseline interview for older men and women. As shown in Table 1, approximately 76 percent of older men reported no problem to perform any ADL items at the baseline (Wave I). On the other hand, twothirds of women reported no functional problem at the baseline interview. The number of people decreased as the number of ADL limitations increased. For both men and women, the death rate of each ADL category showed a general increase as the number of ADL limitations became larger. The death rate for each category of the number of ADL limitations was generally higher for men than women except for these with six ADL limitations. The overall death rate for persons with any ADL limitations was higher for men (25.0\%) than women $(18.1 \%)$.

As shown in Table 2, the highest percentage in the condition of some difficulty or problem at each ADL function for men was for walking (26.8\%), and toileting was the lowest $(3.1 \%)$. Approximately 10 percent of men who reported no problem in performing ADL had deceased in each ADL item. On the other hand, men with some ADL problem showed higher percentages in mortality than their counterparts in each ADL category. Approximately 25 percent to 38 percent of men who had an ADL limitation at the baseline deceased within two years.

For women the highest percentage in the condition of some difficulty or problem at each ADL function was for walking $(26.8 \%)$, and toileting and eating were the lowest (5.7\%). Compared with men, lower mortality rates for women for both with and without limitation in each ADL category were observed. Approximately six to eight percent of

Table 1. Activities of daily living (ADLs) profile for men and women who were age 70 or over at the baseline interview: 1994.

\begin{tabular}{|c|c|c|c|c|}
\hline & \multicolumn{2}{|c|}{ Men } & \multicolumn{2}{|c|}{ Women } \\
\hline & $\begin{array}{c}\text { Wave I } \\
\text { Frequency }(\%)\end{array}$ & $\begin{array}{c}\text { Wave II } \\
\text { Deaths (\%) }\end{array}$ & $\begin{array}{c}\text { Wave I } \\
\text { Frequency }(\%)\end{array}$ & $\begin{array}{c}\text { Wave II } \\
\text { Deaths }(\%)\end{array}$ \\
\hline Total & $2,908 \quad(100.0)$ & $362(12.4)$ & $4,535(100.0)$ & $433(9.5)$ \\
\hline \multicolumn{5}{|c|}{ Number of ADL help/difficulty } \\
\hline None & $2,163(75.8)$ & $176(8.1)$ & $3,013(66.8)$ & $157(5.1)$ \\
\hline 1 & 337 (11.2) & $61(17.4)$ & $659(14.5)$ & $77(12.4)$ \\
\hline 2 & $167(5.4)$ & $43(24.9)$ & $309(6.8)$ & $52(16.8)$ \\
\hline 3 & $92(3.1)$ & $29(30.0)$ & $204(4.4)$ & $31(16.2)$ \\
\hline 4 & 51 (1.6) & $17(25.7)$ & $146(3.2)$ & $37(24.4)$ \\
\hline 5 & $43(1.2)$ & $12(33.2)$ & $99(2.0)$ & $30(31.0)$ \\
\hline 6 & $55(1.7)$ & $24(43.9)$ & $105(2.3)$ & $49(44.9)$ \\
\hline Any ADL problem & $745(24.2)$ & $186(25.0)$ & $1,522(33.2)$ & $276(18.1)$ \\
\hline
\end{tabular}

Percentages in parentheses are weighted. Percentages for deaths are for each category. 
women who reported no problem in performing $\mathrm{ADL}$ at the baseline had deceased within two years in each ADL category. Women with some ADL problem in each ADL category showed approximately 20 to 33 percent of mortality rates. However, each mortality rate was higher than the ones without any problem for each ADL category for women as compared with men's cases.

The odds ratios (ORs) of the two-year death as an outcome for the number of ADL difficulties against no ADL problem at baseline are shown in Table 3. In the models for both men and women demographic factors (i.e., age, rage, and marital status) were controlled. Any number of ADL difficulties were significantly related to the death of two-year duration for both men and women. For instance, the odds of being deceased within two years for older men was 1.88 times higher $(p<0.001)$ if they had one ADL problem than for men who did not have any ADL problem. Men who reported problems in all six ADL categories showed approximately seven times higher odds to be deceased within two years than men with no ADL problem at the significant level of $p<0.001$. For women, the odds of being deceased within two years for individuals with one ADL problem was 2.17 times higher $(p<0.001)$ than for those who reported no ADL problem at baseline $(p<0.001)$.
Women who reported problems in all six ADL items showed significantly higher odds of being deceased within two years $(\mathrm{OR}=11.4$ at $p<0.001)$ than women with no ADL problems at the baseline interview to be deceased.

Multivariate logistic regression analyses for each ADL item showed some significant results for both sexes (Table 4). For men, problems in walking, dressing, or bathing were related to dying within two years. Men with walking problems had 1.61 times higher odds $(p<0.01)$ than ones with no walking problem to be deceased in two years. Men with some difficulty in dressing showed 1.64 times higher odds $(p<0.05)$ to be deceased within two years than men who reported no problem in dressing at the baseline. Bathing problems for men also indicated higher odds $(\mathrm{OR}=1.89$ at $p<0.01)$ of twoyear death than men without such a problem. On the other hand, women showed significant relations between problems in walking, bathing, bedding, or eating and death of two-year duration. Walking problems for women had 1.77 times higher odds $(p<0.001)$, than women with no walking problems, to die within two years. Problems in bathing, bedding, or eating for women indicated respectively, $1.56(p<0.01), 1.42(p<0.05)$, and $1.68(p<0.01)$ times higher odds to be deceased within two years than women without such problems in each cat-

Table 2. Two-year transition of six ADL categories for men and women who were aged 70 and over in a non-institutionalized setting.

\begin{tabular}{|c|c|c|c|c|c|c|}
\hline & \multicolumn{3}{|c|}{$\begin{array}{c}\text { Men } \\
\mathrm{n}=2,908\end{array}$} & \multicolumn{3}{|c|}{$\begin{array}{l}\text { Women } \\
\mathrm{n}=4,535\end{array}$} \\
\hline & Difficulty & $\begin{array}{c}\text { Wave I } \\
\text { Frequency }(\%)\end{array}$ & $\begin{array}{c}\text { Wave II } \\
\text { Deaths }(\%)\end{array}$ & Difficulty & $\begin{array}{c}\text { Wave I } \\
\text { Frequency }(\%)\end{array}$ & $\begin{array}{c}\text { Wave II } \\
\text { Deaths }(\%)\end{array}$ \\
\hline \multirow[t]{2}{*}{ Walking } & No & $2,324 \quad(73.2)$ & $210(9.0)$ & No & $3,302 \quad(73.2)$ & $197(5.8)$ \\
\hline & Yes & 584 (26.8) & $152(25.0)$ & Yes & $1,233(26.8)$ & $236(19.5)$ \\
\hline \multirow[t]{2}{*}{ Dressing } & No & $2,556 \quad(88.5)$ & $259(9.8)$ & No & $3,879 \quad(85.9)$ & $273(7.2)$ \\
\hline & Yes & 352 (11.5) & $103(28.4)$ & Yes & $656(14.1)$ & $160(23.8)$ \\
\hline \multirow[t]{2}{*}{ Bathing } & No & $2,619 \quad(90.8)$ & $264(9.9)$ & No & $3,859 \quad(85.5)$ & $262(6.9)$ \\
\hline & Yes & $289(9.2)$ & $98 \quad(32.5)$ & Yes & $676(14.5)$ & $171(25.0)$ \\
\hline \multirow[t]{2}{*}{ Bedding } & No & $2,691 \quad(93.3)$ & 302 (10.8) & No & $4,019 \quad(89.0)$ & $301 \quad(7.5)$ \\
\hline & Yes & 217 (6.7) & $60(27.7)$ & Yes & $516(11.0)$ & $132(25.9)$ \\
\hline \multirow[t]{2}{*}{ Eating } & No & $2,757 \quad(95.1)$ & $308 \quad(10.8)$ & No & $4,276(94.3)$ & $344(8.1)$ \\
\hline & Yes & 151 & $54(34.4)$ & Yes & $259(5.7)$ & $89(32.9)$ \\
\hline \multirow[t]{2}{*}{ Toileting } & No & $2,805 \quad(96.9)$ & $323(11.1)$ & No & $4,277 \quad(94.3)$ & $355(8.3)$ \\
\hline & Yes & $103(3.1)$ & 39 (38.3) & Yes & $258(5.7)$ & $78(29.0)$ \\
\hline
\end{tabular}

Number in parentheses indicates weighted percentages. Percentages of Wave II are based on the category of each ADL condition at Wave I. Unknown includes moving, being institutionalized, refused, deceased (may partially include) or others. 
Table 3. Odds ratios in multivariate logistic regression analyses for associations of numbers of difficulty in activities of daily living (ADLs) and demographic factors and two-year death as an outcome for men and women in a noninstitutionalized setting.

\begin{tabular}{lcc}
\hline & $\begin{array}{c}\text { Men } \\
(\mathrm{n}=2,844)\end{array}$ & $\begin{array}{c}\text { Women } \\
(\mathrm{n}=4,457)\end{array}$ \\
\hline Number of deaths & 362 & 433 \\
Age & $1.09 * * *$ & $1.05 * * *$ \\
Race & 1.24 & 1.09 \\
Marital status & 1.17 & 1.26 \\
Number of ADL difficulty & & \\
1 & $1.88^{* * *}$ & $2.17 * * *$ \\
2 & $3.17 * * *$ & $3.03 * * *$ \\
3 & $3.46^{* * *}$ & $2.82^{* * *}$ \\
4 & $3.00^{* *}$ & $4.64 * * *$ \\
5 & $3.87 * * *$ & $6.44 * * *$ \\
$\quad 6$ & $7.01 * * *$ & $11.44 * * *$ \\
\hline -2 Log L & 199.41 & 309.82 \\
$\quad$ df & 9 & 9 \\
Probability & $P<0.001$ & $P<0.001$ \\
\hline
\end{tabular}

Significant level: $* p<0.05 ; * * p<0.01 ; * * * p<0.001$

Reference categories:

Race: whites

Marital status: married or living with a partner

Number of ADL difficulty: none

Missing data are not included.

egory.

\section{DISCUSSION}

People of the same sex who had some ADL problems showed a higher percentage of dying than people without any ADL problems. An increased number of ADL limitations is associated with an increased risk of death. These findings resemble other longitudinal studies ${ }^{8,9)}$. Certain categories of ADL limitations and the number of ADL limitations also predict the death of older men and women while other factors are controlled. A previous study showed that changes in functional level are an important predictor of both death and readmittance to a hospital. It reported that the level of ADLs at admission to a hospital is a strong predictor of death ${ }^{4}$. In our study, we found that walking, dressing, and bathing were independent predictors of death for men, and that walking, bathing, bedding, and eating are independent predictors of death for women in a two-year duration. It should be noticed that numerous people died with-
Table 4. Odds ratios in multivariate logistic regression analyses for associations of activities of daily living (ADLs) and demographic factors and two-year death as an outcome: for men and women in a non-institutionalized setting.

\begin{tabular}{lcc}
\hline & $\begin{array}{c}\text { Men } \\
(\mathrm{n}=2,844)\end{array}$ & $\begin{array}{c}\text { Women } \\
(\mathrm{n}=4,457)\end{array}$ \\
\hline Number of deaths & 362 & 433 \\
Age & $1.09 * * *$ & $1.05 * * *$ \\
Race & 1.24 & 1.08 \\
Marital status & 1.19 & 1.27 \\
Walking & $1.61 * *$ & $1.77 * * *$ \\
Dressing & $1.64 *$ & 1.29 \\
Bathing & $1.89 * *$ & $1.56 * *$ \\
Bedding & 0.64 & $1.42 *$ \\
Eating & 1.47 & $1.68 * *$ \\
Toileting & 1.34 & 1.08 \\
\hline -2 Log L & 200.89 & 303.96 \\
df & 9 & 9 \\
Probability & $P<0.001$ & $P<0.001$ \\
\hline
\end{tabular}

Significant level: $* p<0.05 ; * * p<0.01 ; * * * p<0.001$

Reference categories:

Race: whites

Marital status: married or living with a partner

Walking, dressing, bathing, bedding, eating, and toileting: no help or difficulty

Missing data are not included.

out any profile of ADL limitation. This applied to 176 men (or $8.1 \%$ of men) and 157 women (or $5.1 \%$ of women) who did not have any ADL problems at the baseline interview of our study.

The different death profile for men and women may be influenced by their different functional status. It is suggested that some basic ADLs (such as eating or toileting) are more fundamental to survival than others, and that those who have a problem but do not receive help for the less fundamental ADLs (such as walking or dressing) survive ${ }^{10)}$. Older women show higher prevalence of fundamental ADLs than older men in a community. The different prevalence of fundamental ADLs between men and women would affect the death events differently. Incidence of lethal diseases such as heart attack or stroke may jeopardize older individuals' life or yield disability differently. Some factors such as falls ${ }^{11)}$ or cognitive impairment ${ }^{12)}$ may need to be considered for different profiles of physical disability as well.

In our study, we found missing persons in the outcomes of functional limitation. In general, per- 
sons with ADL limitations and cognitive impairment experienced a two- to three-fold increase in the risk for nursing home admission ${ }^{13)}$. Therefore, although they are small percentages, a certain number of missing persons who reported some problems in performing ADL or had cognitive impairment at the baseline interview might be alive in an institution.

This study gives us information on the relationship between ADL limitations and death. For future studies, it will be helpful if diseases and illness are considered in relation to ADL limitations and death. Furthermore, along with death as an outcome, the dynamics of functional changes along with institutional setting will further a better understanding of functional status among the elderly.

\section{REFERENCES}

1) Katz S, Downs TD, Cash HR, et al.: Progress in development of the index of ADL. Gerontologist, 1970, 10: 20-30.

2) Spector WD, Kapp MC: Patterns of ADL change and hospitalization for elders admitted to nursing homes for the first time: Final report. Providence: Brown University, Long Term Care Gerontology Center, 1987.

3) Branch LG, Katz S, Kniepmann K, et al.: A prospective study of functional status among community elders. Am J Public Health, 1984, 74: 266-268.

4) Manton KG: A longitudinal study of functional change and mortality in the United Status. J Gerontol, 1988, 43: S153-S161.
5) Strawbridge WJ, Kaplan GA, Camacho T, et al.: The dynamics of disability and functional change in an elderly cohort: Results from the Alameda County study. J Am Geriatr Soc, 1992, 40: 799-806.

6) Crimmins EM, Saito Y: Getting better and getting worse: transitions in functional status among older Americans. J Aging Health, 1993, 5: 3-36.

7) Rudberg MA, Parzen MI, Leonard LA, et al.: Functional limitation pathways and transitions in community-dwelling older persons. Gerontologist, 1996, 36: 430-440.

8) Miller B, Prohaska T, Mermelstein R, et al.: Health data on older Americans: United States, 1992. Changes in functional status and risk of institutionalization and death. Vital \& Health Statistics - Series 3, Analytical \& Epidemiological Studies, 1993, pp 4175.

9) Rakowski W, Mor V: The association of physical activity with mortality among older adults in the Longitudinal Study of Aging (1984-1988). J Gerontol, 1992, 47: M122-M129.

10) Prohaska T, Mermelstein R, Miller B, et al.: Health data on older Americans: United States, 1992. Functional status and living arrangements. Vital \& Health Statistics - Series 3, Analytical \& Epidemiological Studies, 1993, pp 23-39.

11) Dunn JE, Rudberg MA, Furner SE, et al.: Mortality, disability, and falls in older persons: the role of underlying disease and disability. Am J Public Health, 1992, 82: 395-400.

12) Barberger GP, Fabrigoule C: Disability and cognitive impairment in the elderly. Disability \& Rehabilitation, 1997, 19: 175-193.

13) Foley DJ, Ostfeld AM, Branch LG, et al.: The risk of nursing home admission in three communities. J Aging Health, 1992, 4: 155-173. 